\title{
Seismic Performance of Irregular Buildings
}

\author{
A. Sujatha* \\ Bharath University, Selaiyur, Chennai, India; sujiash@yahoo.com
}

\begin{abstract}
Modern building planning is influenced by many factors and often, there is a trend to adopt a form that has irregular shape in plan and also has variation in height of storeys. Due to the varied use, a building is planned for; variations in the load acting on different floors may also differ. More irregularities can be present like non continuation of members in all the floors, or absence of members, and also having additional members in some of the storey levels. Such buildings will have maximum risk, when compared to conventional framed structures, when seismic forces come into play. This paper highlights the various aspects in the performance of buildings, and also suggests some remedies for the problems.
\end{abstract}

Keywords: Building Planning, Irregular Buildings, Seismic Performance

\section{Introduction}

Building planning has undergone rapid changes and, nowadays, planners are experimenting with all sorts of new materials for construction. The concept of multi use buildings has put the planner to adopt buildings of varied height in several storeys. The effect of earth quakes on buildings is well known. The inertial forces, acting on the buildings due to earth quake vibrations, may case the building to vibrate at frequencies which may vary in intensity at different aspects of time. The performance of a building under the influence of earthquake forces will depend upon its stiffness, ductility of the building materials used, and also the distribution of the mass across the length and breadth of the building. The height of the building and its width also plays an important role in its seismic performance.

\section{Irregular Buildings and their Seismic Performance}

Buidings, which have more length compared to its width, fare better in terms of seismic performance. Slender buildings, which have less width but more height is found to sustain more damage during an earth quake than buildings which have more width. Buildings with reentrant corners, and also those, which lack in symmetry in the plan shape also, fare badly during earth quakes ${ }^{2}$.

Buildings, which have different loads in different storeys, will shake at different amplitudes at different levels, and this may result in structural damage in the building, if the vibrations exceed the natural frequency of the building components. Due to the variations in the terrain level, height of columns vary at the ground floor level for certain buildings. Such buildings have a tendency to buckle and fail during earthquake intensity. The difference in height of several storeys leads to great difference in stiffness at each level and may induce seismic damage.

The effects of seismic forces on the irregular buildings are twisting, overturning, damage to nonstructural elements, and also damage to structural elements etc.

\section{Measures to Improve Better Seismic Performance of Irregular Buidings}

Some of the considerations for better seismic performance of buildings ${ }^{1}$ are:

1. Having better width to height ratio for the buildings

2. Having symmetrical plan

${ }^{*}$ Author for correspondence 
3. Introduction of shear walls, wherever needed

4. Improving ductility at places where stiffness is more

5. Adopting same height in all storey levels

6. Having better distribution in mass at all floor levels

\section{Conclusion}

The performance of irregular buildings under seismic effects will be a problem unless precautionary measures are taken. Irregular buildings need better planning and precautions, while planning for its seismic performance.

\section{References}

1. Bureau of Indian Standards, Criteria for earthquake design of structures, Part-1\&2. 2002; BIS1893-2002.

2. Moorthy. IIT Kanpur Tips. 